\title{
RENK ARMONILERININ TEORISi
}

Yazar

Semra DOĞAN AK 


\section{(C) Copyright 2020}

Bu kitabın, basım, yayın ve satış hakları Akademisyen Kitabevi A.Ş.'ne aittir. Anlan kuruluşun izni alınmadan kitabın tümü ya da Bölümleri mekanik, elektronik, fotokopi, manyetik kağıt ve/veya başka yöntemlerle çoğaltılamaz, basılamaz, dağıtılamaz. Tablo, şekil ve grafikler izin alınmadan, ticari amaçh kullanılamaz. Bu kitap T.C. Kültür Bakanlı̆̆ bandrolü ile satılmaktadır.

ISBN

978-625-7707-73-2

Kitap Adı

Renk Armonilerinin Teorisi

Yazar

Semra DOĞAN AK

ORCID iD: 0000-0002-3842-682X

Yayın Koordinatörü

Yasin Dilmen

Sayfa ve Kapak Tasarımı

Akademisyen Dizgi Ünitesi

Yayıncı Sertifika No

47518

Baskı ve Cilt

Vadi Matbaacilık

Bisac Code

ART007000

\section{GENEL DAĞITIM Akademisyen Kitabevi A.Ş.}

Halk Sokak 5 / A

Yenişehir / Ankara

Tel: o312 4311633

siparis@akademisyen.com 


\section{ÖNSÖZ}

Rengin fiziksel yapısı ve rengin insan psikolojisi üzerine etkileri uzun bir dönemin araştırma konusu ve ilgi odağı olmuştur. Mimari düzenlemeler ve iç mimarlığın insan duygulanımını göz ardı etmeyen araştırmaları sonucu, dış mekan ve iç mekan düzenlemesinde renk seçimi çok önemsenmektedir. Renklerin simgesel anlamları bile bayrakların oluşum aşamasında uzun tartışmalar sonucu karar kılınıp sonuçlandırılmıştır. Uzay teleskoplarının yapımında kullanılan ve askeri malzemelerin görünmezlik illüzyonu gerektiren araçları için bulunmuş, ş̧ı̆̆ yansıtmayan ve dünyanın en koyu siyahı 'vantablack'in bulunuşu da bir ihtiyaç sonucu kullanılmaktadır.

Bir ressam olarak rengin hem nasıl bulunduğu, hem de nasıl elde edildiği ilgimi çok çekmiştir. Renk konusu hakkında araştırma yapmaya başladığımda büyük bir inceleme konusu ve envanter ile karşı karşıya kaldım. Her dönemin ve sanatçının kendi eserleri üretim aşamasında renk ile ilişkisi farklı olmuştur. En çok ilgimi çeken konu ise renk ile ilgili derinlemesine araştırmaların aslında fizik, kimya ve psikoloji alanında etkili olan bilim insanlarının araştırma yapmış olduğunu keşfetmem olmuştur. Küçüklüğümde renklerin aslında salt gördüğümüz şekilde olmadığını, nesnelerin ışık dalgalarını absorbe etmesi ve yansıması sonucu gözümüze gelen ışığın algısı sonucu görülebildiğini öğrendiğimde çok etkilenmiştim. Rengin görülebilmesi bitki, hayvan ve nesnelerdeki bazı proteinlerin yapısı üzerinde ışı̆̆ın yansıması ile ortaya çıkmaktaydı. Çocukluğumda, Bulgaristan'da babaannemin yanına köye sık sık gidiyordum ve komşusunun bir sürüngenler ve böcekler ansiklopedisi vardı. O kitabı her gittiğimde yutarcasına incelediğimi hatırlyyorum. Hafızamda en fazla yer etmiş olanları ise parlak renkli semenderler ve kelebeklerdi. Onların en zehirli olanları 
olduklarını öğrendiğimde bunun renklerinden dolayı olduğunu düşünmüştüm.

Tüm öğrencilik ve akademisyenlik dönemimde renk ile olan ilişkim sonucunda ilgim hep yoğundu ve kızım doğduğunda adını Renk olarak seçtim. Bu ismin benim ve ailem için özel bir anlamı olmuştur, dolayısı ile bu kitabı üç yaşında olan kıymetli kızımın adına ithaf ediyorum. Tüm bu süreç içerisinde hem bana ve k1zıma bakma, büyütme döneminde sınırsız ilgi gösteren, yazıma başlamamda en büyük destekçim olan eşime minnettarlığımı vurgulamak istiyorum.

Konuya olan ilgimi, biriktirdiğim envanteri derleme ihtiyac1 hissettiğimde, aslında hep bu soru ile karşılaştım: "Yirmi dört renk teorisi vardır. Kimdir bu renk teorisyenleri?” Belli başlı isimler dışında diğer teorisyenler bilinmemektedir ve bu konuda bir derleme ile karşılaşamadım. Bu nedenle her teorisyenin araştırmasının çok kıymetli ve ilgi çekici, birbirlerini etkileyen ve ardılı olan bilim insanları, sanatçılar olduklarını fark ettim. Bu derlemenin renk araştırmaları konusunda ve geldiğimiz sonuç ile nerede bulunduğumuzu bir zaman çizelgesi titizliği ile toplama ihtiyacı hissettim. Bu araştırmanın plastik sanatlar alanında bilimsel ve sanatsal kaynak kitabı olacağına inanarak sizlerle paylaşıyorum. 


\section{IÇiNDEKILER}

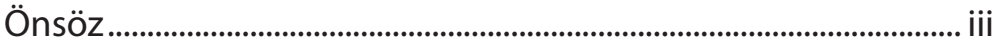

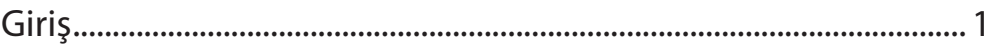

\section{RENGIN YAPISI}

Rengin Tanımı ......................................................................................... 3

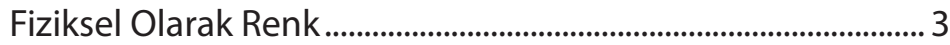

Fizyolojik Olarak Renk........................................................................ 4

Psikolojik Olarak Renk...................................................................... 4

Duyum ve Algılama.......................................................................... 5

Bilinçaltı Algılama .......................................................................... 6

Renk Sürekliliği ....................................................................................... 7

Yansıma Renkleri ................................................................................. 7

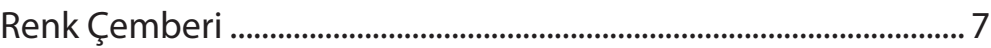

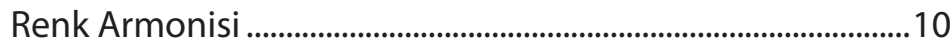

Renk Doygunluğu (Renk Yeğinliği) ...............................................10

Renk Boyutları .....................................................................................10

Renk Tonu (Hue) ........................................................................10

Doygunluk (Saturasyon) .........................................................10

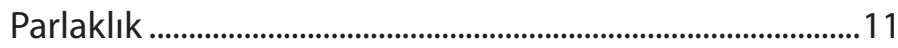

Kromatik Nitelik ................................................................................ 11

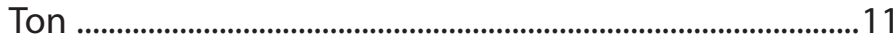

Koyu Değer (Gölge) ..................................................................11

Açık Değer (Tint)...........................................................................12

Soğuk - Sıcak Renkler...............................................................12

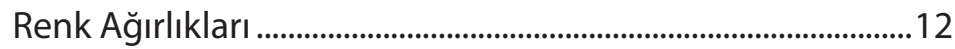

Renkte Ölçü ..........................................................................................12

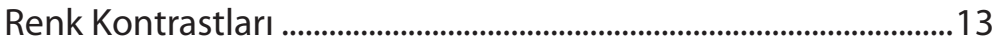

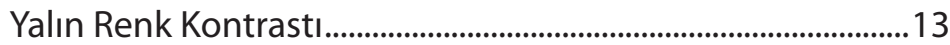


Tamamlayıcı (Complementer) Renk Kontrastı ..........................13

Açık- Koyu Kontrastı .......................................................................14

Sıcak- Soğuk Renk Kontrastı..........................................................15

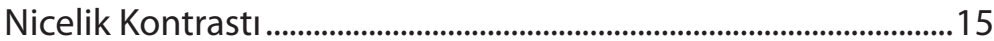

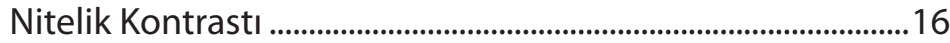

Yanıltıcı (Simultan) Renk Zıtlığı.......................................................17

\section{RENK TEORILERI}

Renk Teorileri Nelerdir? ..................................................................18

Antik Dönemde Renk Teorileri..........................................................21

Pythagoras, Aristhoteles, Platon ..............................................21

Rönesans Döneminde Renk Teorileri ..............................................23

Leon Battista ALBERTI ..................................................................23

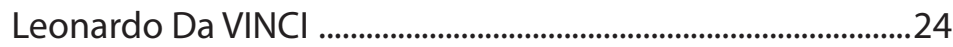





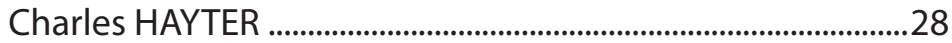

Modern Dönemde Renk Teorileri ...................................................29

Johann Wolfgang VON GOETHE ...............................................29

Michele Eugene CHEVREUL ......................................................32

Eugene DELACROIX ........................................................................36

Young-Helmholtz ..............................................................................

Ewald HERING ............................................................................ 41

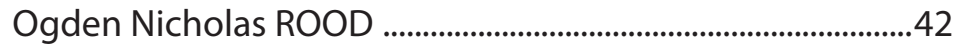

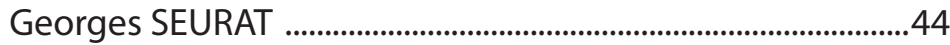

Friedrich Wilhelm OSTWALD..........................................................47

Johannes ITTEN ..............................................................................48

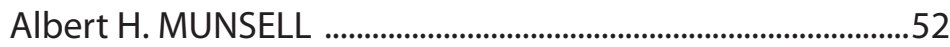

Wassily KANDINSKY ........................................................................53 


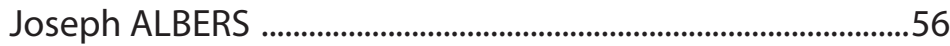

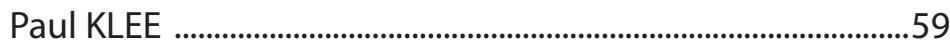

\section{RENK DENINCE}

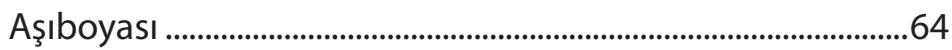

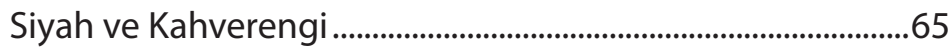

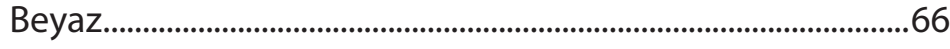

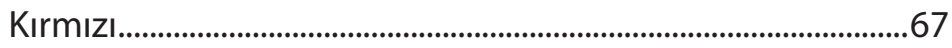

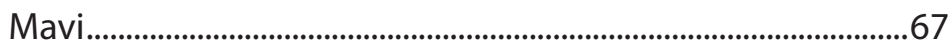

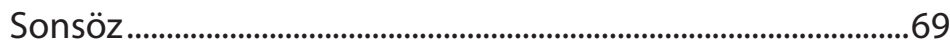

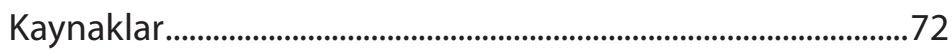




\section{KAYNAKLAR}

AKKAYA, Cahit, Yeni-Dışavurumcu Resimde Şiddetin ve Gerilimin İfade Aracı Olarak Renk, Yüksek Lisans Tezi, Dokuz Eylül Üniversitesi, 2007, İzmir.

ALBERS, Joseph, Rengin Etkileşimi, çev: Gamze Rastgeldi, Birinci Basım, Hayalperest Yayınevi, 2020, İstanbul.

ARTUN Ali - ALİÇAVUŞOĞLU, Esra (Editör), Bauhaus: Modernleşmenin Tasarımı, Türkiyede Mimarlık, Sanat, Tasarım Eğitimi ve Bauhaus, Birinci Baskı, İletişim Yayınları, 2009, İstanbul.

CEVİZCI, Ahmet, Sokrates, Üçüncü Basım, Say Yayınları, 2011, İstanbul.

COŞKUN, Necla, Resim Sanatında Renk-Öz Bağlantıları, Sanatta Yeterlilik Tezi, Anadolu Üniversitesi, 2006, Eskişehir.

ÇİTOĞLU, Sema, 1945 Yılı Sonrası Afişlerdeki Renklerin Psikolojik Boyutları, Yüksek Lisans Tezi, Grafik Eğitimi Bilim Dalı, Eğitim Bilimleri Enstitüsü, Gazi Üniversitesi, 2008, Ankara.

ERBAŞ, Özlem, Sanat Eğitiminde Renk ve Renk Öğretim Yolları, Sanatta Yeterlilik Tezi, Anadolu Üniversitesi, 1996, Eskişehir.

FINLAY, Victoria, Renkler Boya Kutusunda Yolculuklar, çev: Kudret Emiroğlu, Birinci Basım, Dost Yayınevi, 2007, Ankara.

HARRISON, Charles, WOOD, Paul, Sanat ve Kuram 1900-2000 Değişen Fikirler Antolojisi, çev: Sabri Gürses, Birinci Basım, Küre Yayınları, 2011, İstanbul.

KANDINSKY, Vassily, Sanatta Zihinsellik Üzerine, çev: Tevfik Turan, Birinci Basım, Hayalbaz Kitap Yayınları, 2009, İstanbul.

KAVAZ, Elif, Plastik Bir Değer Olarak Işığın İşlevi ve Önemi, Yayımlanmış Yüksek Lisans Tezi, Atatürk Üniversitesi, Sosyal Bilimler Enstitüsü, Resim Anasanat Dalı, Erzurum, 2007

KESER, Nimet Ertaş, Sanat Sözlüğü, İkinci Baskı, Ütopya Yayınları, 2009, Ankara.

KLEE, Paul, Bauhaus Ders Notları ve Yazılar, çev: Uluer Emre Özdil, Birinci Baskı, Hayalbaz Kitap Yayınları, 2010, İstanbul.

KRAUSSE, Anna-Carola, Rönesans’tan Günümüze Resim Sanatının Öyküsü, çev: Dilek Zaptcıoğlu, Literatür Yayınevi, 2005, İstanbul. 
KÜÇÜKÖNER, Mustafa, Renk ve İmge, Yayımlanmış Yüksek Lisan Tezi, Sosyal Bilimler Enstitüsü, Resim Anasanat Dalı, Atatürk Üniversitesi, Sosyal Bilimler Fakültesi, 1998, Erzurum.

NUHOĞLU, Rana, Rengin Tüketici Satın Alma Davranışlarına Etkisi, Yayımlanmış Yüksek Lisans Tezi, Marmara Üniversitesi, Sosyal Bilimler Enstitüsü, İşletme Anabilim Dalı, Üretim Yönetimi ve Pazarlama Bilim Dalı, 2006, İstanbul.

TURANİ, Adnan, Sanat Terimleri Sözlüğü, Onikinci Baskı, Remzi Kitabevi, 2007, İstanbul.

WESTFALL, Richard S. Modern Bilimin Oluşumu, çev: İsmail Hakkı Duru, Dördüncü Basım, Tübitak Popüler Bilim Kitapları, 1995, Ankara.

WÖLFFLIN, Heinrich, Sanat Tarihinin Temel Kavramları, çev: Hayrullah Örs, Üçüncü Baskı, Remzi Kitabevi, 1990, İstanbul.

\section{İnternet Kaynakçası}

HOLDSWORTH, Anthony, Basic Color Theory, 2005, Erişim tarihi: 28 Haziran 2011, Antony Holdsworth web sitesi,

http://www.anthonyholdsworth.com/trying/wpcontent/uploads/2009/01/colortheoryoptimized.pdf

ITTEN, Johannes, Art and Color, (Elektronik sürüm),Google Boks, Erişim tarihi: 28 Haziran 2011,

http://www.google.com/books?hl=tr\&lr=\&id=ofvRhNBgoCoC\&o$\mathrm{i}=$ fnd \&pg $=$ PA $6 \& \mathrm{dq}=$ color + theories + Faber + Birren\&ots $=$ XIV 4sQcJTY\&sig=cU8GXONyskVLFLbU2Q6F5b9pBvc\#v=onepage\&q\&f=true

ITTEN, Johannes. The Elements of Color. 1970, Van Nostrand Reinhold company, USA. say: 53. https://monoskop.org/images/4/46/ Itten_Johannes_The_Elements_of_Color.pdf (erişim tarihi: 04 Kasim 2020).

https://www.winsornewton.com/na/articles/art-history/ostwald-bauhaus-colour-system/ (erişim tarihi: 05 Kasım 2020).

Modern Chromatics, googlebooks. https://books.google.com.tr/books?id=IyAaAAAAYAAJ\&pg=PA228\&hl=tr\&source=gbs_selected_pages\&cad $=3 \# \mathrm{v}=$ onepage\&q\&f=false (erişim tarihi: $04 \mathrm{Kasım}$ 2020). 
Chevreul, Michele Eugene, Principles of Harmony and Contrast of Colours, Googlebooks, https://books.google.com.tr/books?id=LIMOAAAAQAAJ\&pg=PA1\&hl=tr\&source $=$ gbs_toc_r\&cad $=4 \# \mathrm{v}=$ onepage\&q\&f=false (erişim tarihi: 03 Kasım 2020).

Modern Chromatics, Googlebooks. https://books.google.com.tr/books?id=IyAaAAAAYAAJ\&pg=PA228\&hl=tr\&source=gbs_selec ted_pages\&cad $=3 \# \mathrm{v}=$ onepage\&q\&f=false (erişim tarihi: 04 Kasım 2020).

Goethe, JohannWolfgang von, Theory of Colours, Google-books, say:5 https://books.google.com.tr/books?id=qDIHAAAAQAAJ\&print$\mathrm{sec}=$ frontcover\&hl=tr\&source $=\mathrm{gbs} \_g e \_s u m m a r y \_r \& c a d=0 \# \mathrm{v}=0$ nepage\&q\&f=false erişim tarihi: 03 Kasım 2020).

Leon Battista Alberti, On Painting, https://books.google.com.tr/books? id=sVGZtXjRXPAC\&pg=PA50\&lpg =PA50\&dq=\%22Red $+\mathrm{is}+\mathrm{t}-$ he+colour+of+fire, +blue+of+the+air,+green+of+the+water,+an$\mathrm{d}+$ of + the + earth + grey+and + ash. $\% 22 \&$ source $=$ bl\&ots $=Z-0$ c $65 n-$ h5W \&sig=64JrK01K2LvE5NbZgCODnucfHyY\&hl=en\&sa=X\&e$\mathrm{i}=\mathrm{NVP}$ _T-3zEqfO2gXt-tj-Aw\&redir_esc $=\mathrm{y} \# \mathrm{v}=$ onepage\&q\&f=false (erişim tarihi: 30 Ekim 2020).

Colorsystem in Art and Science; https://www.colorsystem.com/?page $\mathrm{id}=31$ \&lang=en (erişim tarihi: 30 Ekim 2020).

J.L. Benson, Greek Color Theory, University of Massachussetts Amherst, https://scholarworks.umass.edu/art_jbgc (erişim tarihi: 30 Ekim 2020).

https://bibliotheque-numerique.citedulivre-aix.com/viewer/35315/?offset $=\#$ page $=108 \&$ viewer $=$ picture $\& o=$ bookmarks $\& n=0 \& q=($ erişim tarihi: 03 Kasim 2020). 